\title{
Chromosomal relationships among the native rodents (Cricetidae: Oryzomyini) of the Galápagos Islands, Ecuador
}

\author{
Robert C. Dowler ${ }^{1 *}$ and Marcia A. Revelez ${ }^{2}$ \\ ${ }^{1}$ Department of Biology, Angelo State University, San Angelo 76909. Texas, USA. E-mail: robert.dowler@angelo.edu. \\ ${ }^{2}$ Museum of Texas Tech University, Lubbock 76409-3191. Texas, USA, E-mail: marcia.revelez@gmail.com. \\ *Corresponding author
}

\begin{abstract}
Although the Galápagos Islands are recognized for their contribution to our understanding of evolutionary theory and have received the attention of scientists for over 185 years, our understanding of the native rodents there has been minimal relative to many other groups of organisms. Much of what we knew through most of the $20^{\text {th }}$ century was based solely on species descriptions. Chromosome data has been limited to only Nesoryzomys narboroughi $(2 \mathrm{n}=32, \mathrm{FN}$ (number of autosomal arms) $=50$ ) and Aegialomys galapagoensis $(2 \mathrm{n}=56 ; \mathrm{FN}=58)$. We present the karyotypes of the only remaining extant species in the genus, $N$. swarthi $(2 \mathrm{n}=56 ; \mathrm{FN}=54)$ and $N$. fernandinae $(2 \mathrm{n}=44 ; \mathrm{FN}=54)$. Chromosomal banding reveals that extensive rearrangement has occurred within Nesoryzomys, including Robertsonian fusion and tandem fusion events but these alone cannot account for the diverse diploid numbers found within the genus. We propose that 1) N. swarthi represents the ancestral karyotype for the genus, similar to A. galapagoensis, 2) N. swarthi and N. fernandinae share the same fundamental number, suggesting divergence by Robertsonian fusions, and 3) N. narboroughi has the most derived karyotype, based on banding morphology and low diploid number.
\end{abstract}

Aunque las Islas Galápagos son reconocidas por su contribución a nuestra comprensión de la teoría de la evolución y han recibido la atención de los científicos durante más de 185 años, nuestra comprensión de los roedores nativos de dichas islas, ha sido mínima en comparación con muchos otros grupos de organismos. Gran parte del conocimiento obtenido durante la mayor parte del siglo XX se basó únicamente en descripciones de especies. Los datos cromosómicos se han limitado solo a Nesoryzomys narboroughi ( $2 \mathrm{n}=32$, FN (número de brazos autosómi$\cos )=50)$ y Aegialomys galapagoensis $(2 n=56 ; F N=58)$. Presentamos los cariotipos de las únicas especies que quedan en el género, $N$. swarthi $(2 \mathrm{n}=56 ; \mathrm{FN}=54)$ y $N$. fernandinae $(2 \mathrm{n}=44 ; \mathrm{FN}=54)$. El método de bandeo cromosómico revela que se ha producido un reordenamiento extenso dentro de Nesoryzomys, incluida la fusión robertsoniana y los eventos de fusión en tándem, pero estos por sí solos no pueden explicar los diversos números diploides que se encuentran dentro del género. Proponemos que 1) N. swarthi representa el cariotipo ancestral del género, similar a A. galapagoensis, 2) N. swarthi y N. fernandinae comparten el mismo número fundamental, lo que sugiere una divergencia por fusiones robertsonianas y 3) $N$. narboroughi tiene el cariotipo más derivado, basado en la morfología de bandas y en el bajo número diploide.

Keywords: Aegialomys; chromosomal rearrangements; G-bands; karyotypes; Nesoryzomys.

(c) 2021 Asociación Mexicana de Mastozoología, www.mastozoologiamexicana.org

\section{Introduction}

The Galápagos Islands have played a critical role in our understanding of evolution and have been the focus of thousands of studies dealing with the unique flora and fauna of this archipelago (Snell et al. 1996). Despite this, the rodent fauna has been poorly represented in scientific research relative to many Galápagos vertebrates. Until the late $20^{\text {th }}$ century, original species descriptions were almost the only research published. This taxonomy of the native rodents has had a circuitous history with name changes at both the genus and species levels. Only a single study (Gardner and Patton 1976) has described cytogenetic data.

Taxonomic history of Galápagos rodents. Charles Darwin collected the first native rodents in the Galápagos Islands in 1835 on the island of Chatham (now known as San Cristóbal; Figure 1). The species, later described by Waterhouse (1839) as Mus galapagoensis (=Aegialomys galapagoensis), was never collected again on San Cristóbal (Clark 1984). Allen (1892) described a second species, Oryzomys bauri from the island of Barrington (now Santa Fé), recognizing both bauri and galapagoensis as belonging to the genus Oryzomys. In 1899, Oldfield Thomas described the first rodent from the island of Indefatigable (now Santa Cruz) as Oryzomys indefessus, and Heller (1904) later elevated this species to a separate genus, Nesoryzomys, on the basis of skull morphology. A second species within the genus, N. narboroughi, also was described by Heller (1904) on the westernmost island, Narborough (now Fernandina). Osgood (1929) described a third, smaller species, N. darwini, from Santa Cruz and Orr (1938) described another large form, N. swarthi, from James Island (now Santiago). A fifth species in the genus, N. fernandinae, was described in 1979 based on owl pellet remains from the island of Fernandina (Hutterer and Hirsch 1979) and was small in body size.

In 1983, Patton and Hafner published the most comprehensive systematic treatise on Galápagos rodents to date, summarizing the systematic relationships based on cranial, stomach and male reproductive tract morphology, pelage color, allozymes, and karyotypes. Despite the number of data sets analyzed, their study was hampered because at the time the manuscript was written, only 2 native species of rodents, Nesoryzomys narboroughi and Oryzomys bauri, were known to be extant. Nesoryzomys swarthi was known from four specimens in the type series 
collected in 1906 (Orr 1938) and a single skull collected in 1965 (Peterson 1966); however, the species was considered extinct by most (Patton and Hafner 1983; Clark 1984). Both N. indefessus on Santa Cruz and Baltra, and $N$. darwini on Santa Cruz had been considered extinct since the 1940's (Brosset 1963; Clark 1984; Key and Muñoz 1994). Nesoryzomys fernandinae, described solely on skulls (Hutterer and Hirsch 1979), could not be included in the study by Patton and Hafner (1983) as the species had not yet been described at the time the manuscript was submitted. The analysis of available data by Patton and Hafner (1983) suggested that the large-bodied Nesoryzomys, represented by N. indefessus, N. narboroughi, and $N$. swarthi, were variants of a single species that should be recognized as $N$. indefessus and that Oryzomys bauri and O. galapagoensis should be synonymized with O. galapagoensis having priority. Musser and Carleton (2005) concurred, placing narboroughi and indefessus in synonymy under $N$. indefessus, but recognizing $N$. swarthi as a valid taxon. Most recently, in revisions of oryzomyines (Weksler 2006; Weksler et al. 2006), Nesoryzomys was retained as a valid genus, but Oryzomys galapagoensis was placed with O. xanthaeolus in the genus Aegialomys (Prado and Percequillo 2018). Currently, the Galápagos native rodents are composed of A. galapagoensis, N. darwini, N. fernandinae, $N$. indefessus and N. swarthi, following Musser and Carleton (2005). Nesoryzomys narboroughi was recognized as a fifth species of the genus by Dowler (2015). Herein, we treat the genus Nesoryzomys as including five named species. Three additional undescribed species based on fossil remains are known from the islands of Rábida and Isabela (Steadman et al. 1991) but Moreira et al. (2020) reported only one from both of these islands. In addition to these Galápagos species, fossil remains of giant rats, genus Megaoryzomys, are known from Santa Cruz and Isabela (Steadman and Ray 1982; Steadman et al. 1991).

Chromosomes of Galápagos rodents. The only chromosomal data for native Galápagos rodents were published by Gardner and Patton (1976) for Nesoryzomys narboroughi and Aegialomys galapagoensis. The karyotype of N. narboroughi had a diploid number (2n) of 32 and a fundamental number (FN - number of autosomal arms) of 50 with mostly metacentric chromosomes. Its karyotype was strikingly different from that of $A$. galapagoensis $(2 n=56, F N=58)$ with mostly acrocentric chromosomes. The karyotype of $A$. galapagoensis was reported to be essentially identical to that of $A$. xanthaeolus, a mainland from Peru and Ecuador. Not only was the karyotype of $N$. narboroughi considerably different from A. galapagoensis and A. xanthaeolus, but it was unlike any known oryzomyines at the time. On this basis, Gardner and Patton (1976) confirmed the generic status of Nesoryzomys first proposed by Heller (1904). Additional data from Patton and Hafner (1983) further supported the generic status of Nesoryzomys separate from Oryzomys. Other researchers (Ellerman 1941) have recognized Nesoryzomys as a subgenus of Oryzomys.
Field studies by Angelo State University researchers since 1995 have located living populations (Figure 1) of Nesoryzomys fernandinae on Fernandina (Dowler and Carroll 1996) previously known only from owl pellet material, and N. swarthi, previously considered extinct, on Santiago (Dowler et al. 2000). These discoveries have allowed an analysis of diploid and fundamental numbers of these previously unkaryotyped species. In addition, recent collections of all extant Galápagos species of rodents now permit the first comparison of chromosomal banding patterns to help elucidate the systematic relationships of these species.

\section{Material and Methods}

We surveyed the Galápagos rodent species on the islands of Fernandina, Santiago, and Santa Fé (Figure 1). In addition, we conducted survey trips to the islands of Baltra, Isabela, Rábida, San Cristóbal, and Santa Cruz that have had native rodent species historically or as recent fossils, but were unsuccessful in finding extant populations. Specimens were collected using Sherman live traps or small cage traps. All specimens were prepared as study skins or fluidpreserved specimens and deposited in the Angelo State Natural History Collections (ASNHC) of Angelo State University. Specific localities of capture and voucher specimen numbers are given in Appendix 1.

Up to four individuals were karyotyped from each of the three species of Nesoryzomys and A. xanthaeolus. Metaphase chromosomes were obtained in vivo from bone marrow following Lee and Elder (1980). Standard karyotypes were prepared and stained with conventional Giemsa and 8-10 spreads were examined for each species. Additional slides were prepared and counterstained with 4'6-Diamidine-2'-phenylindole dihydrochloride (DAPI) with antifade mounting reagent for visualization of banded chromosomes. DAPI positive bands are indicative of A-T rich regions of heterochromatin. These banding patterns correspond to G-bands produced by trypsin digestion of chromosomes, and subsequently will be referred to as G-bands (Heng and Tsui 1993).

All chromosomes were examined on an Olympus Vanox epifluorescent microscope (Olympus, Melville, NY, U.S.A.). G-bands were examined using a DAPI filter (excitation 350 to $460 \mathrm{~nm}$; emission, longpass, $520 \mathrm{~nm}$ ). Images were obtained using the SPOTÔ, CCD digital camera and Image Pro7 software package (Leeds Instruments, Irving, TX, USA). DAPI bands were obtained by inversion of the fluorescent image, creating banding patterns along the chromosomes. We examined karyotypes to determine phylogenetic relationships among species within the genus Nesoryzomys. For the purpose of establishing polarity of karyotypic characters, we used Aegialomys as an outgroup as recent molecular analyses have placed Aegialomys sister to Nesoryzomys (Parada et al. 2015; Castañeda-Rico et al. 2019; Brito et al. 2020). 


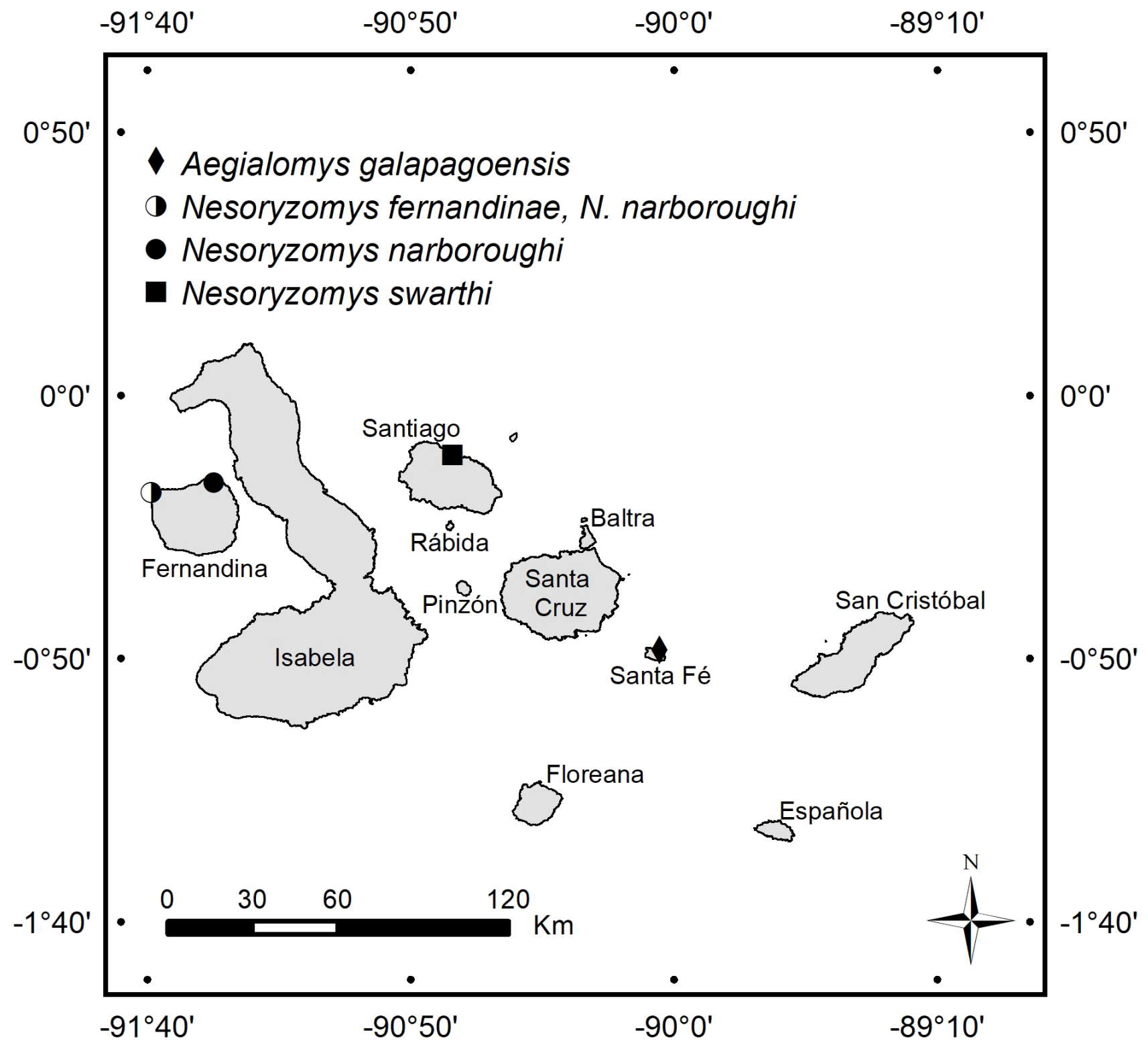

Figure 1. Map of Galápagos Islands, Ecuador with sampling localities of A. galapagoensis (diamond), N. narboroughi (closed circle, half circle), N. swarthi (square), and N. fernandinae (half circle) in the Galápagos Islands.

\section{Results}

Standard Karyotypes. The karyotype for Aegialomys galapagoensis is as previously reported by Gardner and Patton (1976). Aegialomys galapagoensis $(2 \mathrm{n}=56, \mathrm{FN}=58)$ is characterized by one distinctly large acrocentric pair and 24 pairs of acrocentric chromosomes ranging from largeto medium-sized, and two small metacentric pairs. The sex chromosomes, a medium-sized $\mathrm{X}$ and a small $\mathrm{Y}$, are both acrocentric (Figure 2a).

The karyotype of Nesoryzomys narboroughi $(2 n=32$, $\mathrm{FN}=50$ ) presented herein is as described by Gardner and Patton (1976). It comprises eight metacentric pairs ranging from large- to medium-sized chromosomes, two subtelocentric pairs of large- and medium-sized chromosomes, five acrocentric pairs with one large pair and the others small (Figure 2d). The $\mathrm{X}$ and $\mathrm{Y}$ chromosomes are the same as previously described for the genus.

Karyotypic analysis for the previously undocumented extant species of Nesoryzomys revealed strikingly different karyotypes from that of $N$. narboroughi. Unlike the low diploid number found in N. narboroughi, N. swarthi $(2 \mathrm{n}=$ $56, \mathrm{FN}=54$ ) has a karyotype composed completely of 27 pairs of acrocentric chromosomes, with one large pair and 26 pairs ranging from medium to small (Figure $2 b$ ). The $\mathrm{X}$ chromosome is medium-sized and acrocentric, whereas the $\mathrm{Y}$ chromosome is small and acrocentric. Nesoryzomys fernandinae $(2 n=44, F N=54)$ is characterized by six pairs of metacentric chromosomes ranging from large to mediumsized, and one large pair and 14 small pairs of acrocentric chromosomes (Figure 2c). The X chromosome is large and acrocentric and the $\mathrm{Y}$ is a small acrocentric chromosome. 


\section{a

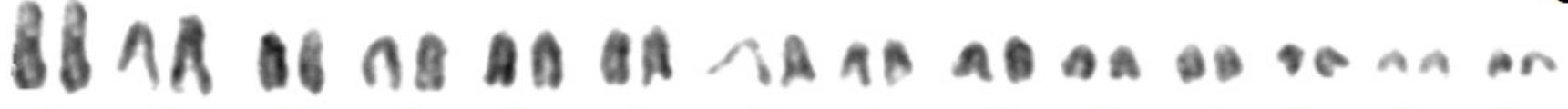

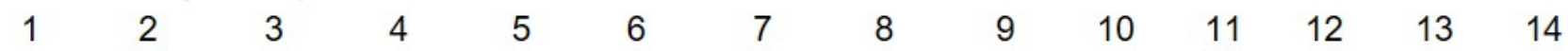 $\neg$ ด $\begin{array}{llllllllllllll}15 & 16 & 17 & 18 & 19 & 20 & 21 & 22 & 23 & 24 & 25 & 26 & 27 & \text { X Y }\end{array}$}

\section{\begin{tabular}{c}
2 \\
\hline
\end{tabular}

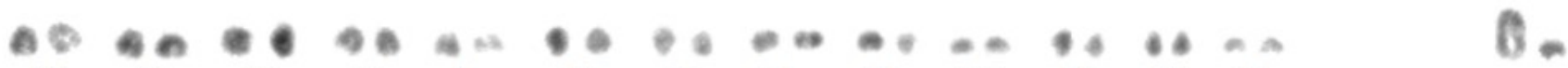

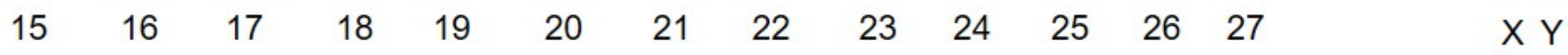

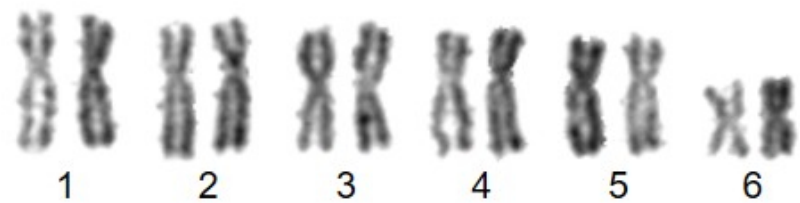

月ी $\begin{array}{lllllllllllllllll}7 & 8 & 9 & 10 & 11 & 12 & 13 & 14 & 15 & 16 & 17 & 18 & 19 & 20 & 21 & X & X\end{array}$

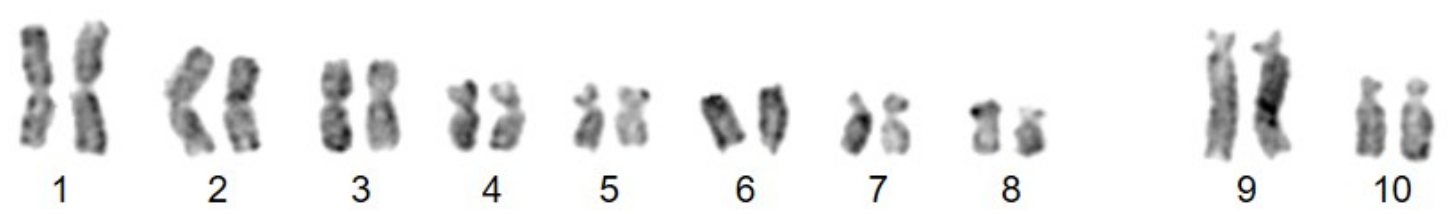

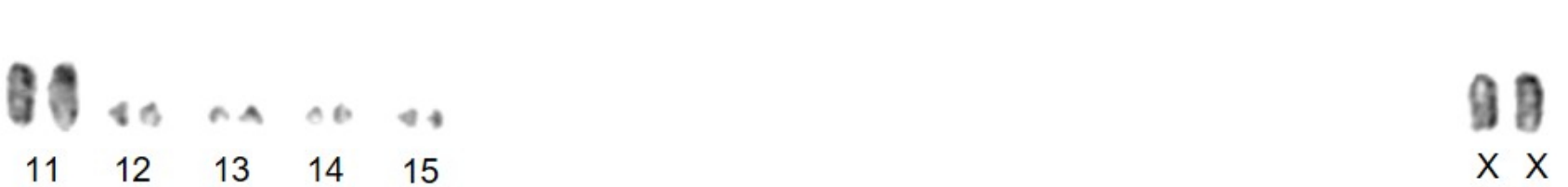

Figure 2. Representative standard karyotypes of the extant native Galápagos rodents. a) Aegialaomys galapagoensis, $2 n=56, F N=58$, male. b) Nesoryzomys swarthi, $2 n=56, F N=54$ male. c) Nesoryzomys fernandinae, $2 n=44$, $F N=54$, female. d) Nesoryzomys narboroughi Heller, $2 n=32, F N=50$, female. Chromosomes are numbered from longest to shortest, beginning with metacentrics and submetacentrics where present.

Banded Karyotypes. G-banded karyotypes (Figure 3) varied in quality but were sufficient to draw some conclusions regarding karyotypic rearrangements responsible for the observed changes in diploid and fundamental numbers. The karyotypes of $N$. swarthi and N. fernandinae have identical fundamental numbers, suggesting Robertsonian rear- rangement events leading to the reduction in chromosome number and the appearance of biarmed chromosomes. Both $N$. fernandinae and $N$. narboroughi are similar in having biarmed chromosomes, but $N$. fernandinae has 15 pairs of acrocentric chromosomes while N. narboroughi has only five. The differences in fundamental numbers suggest tan- 


\section{6. 11 \\ 1 23 \\ 4 \\ 5 \\ $6 \quad 7$ \\ 8 \\ 8 용 8 \\ बै \\ 용 $6 \mathrm{e}$

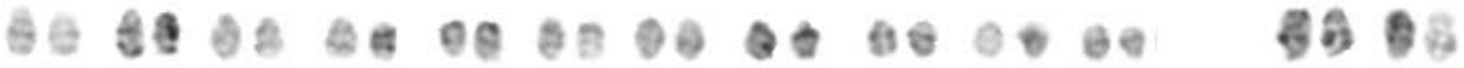
$\begin{array}{lllllllllll}15 & 16 & 17 & 18 & 19 & 20 & 21 & 22 & 23 & 24 & 25\end{array}$
$26 \quad 27$ \\ 1314} a

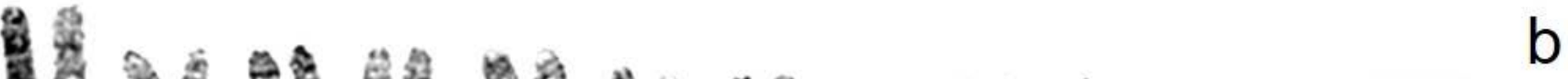

\$ 8

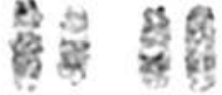

gु

8.

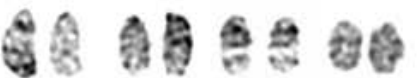

1

2

34

$6 \quad 7$

89

10

1112

$12 \quad 13 \quad 14$

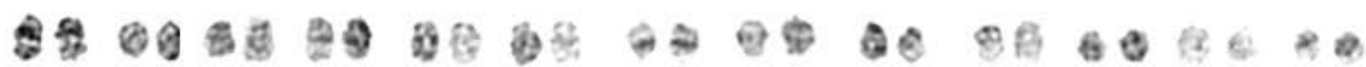

$\begin{array}{lllllllllllll}15 & 16 & 17 & 18 & 19 & 20 & 21 & 22 & 23 & 24 & 25 & 26 & 27\end{array}$
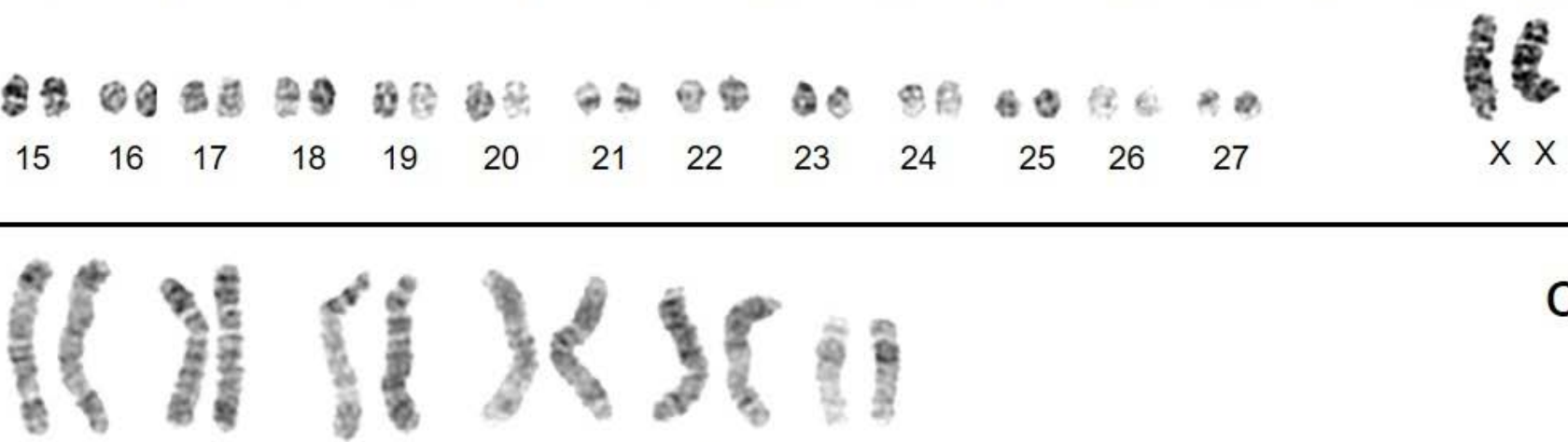

C

1

2

3

4

5

6

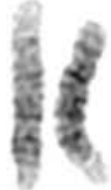

Aิ?

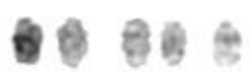

7

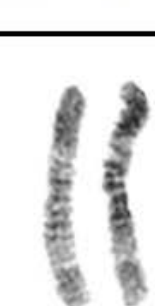

$\begin{array}{lll}10 & 11 & 12\end{array}$

8 e $\mathrm{B}$

하 황

48

(2)

$15 \quad 16$

$16 \quad 17$

$17 \quad 18$

$\begin{array}{llll}8 & 19 & 20 & 21\end{array}$
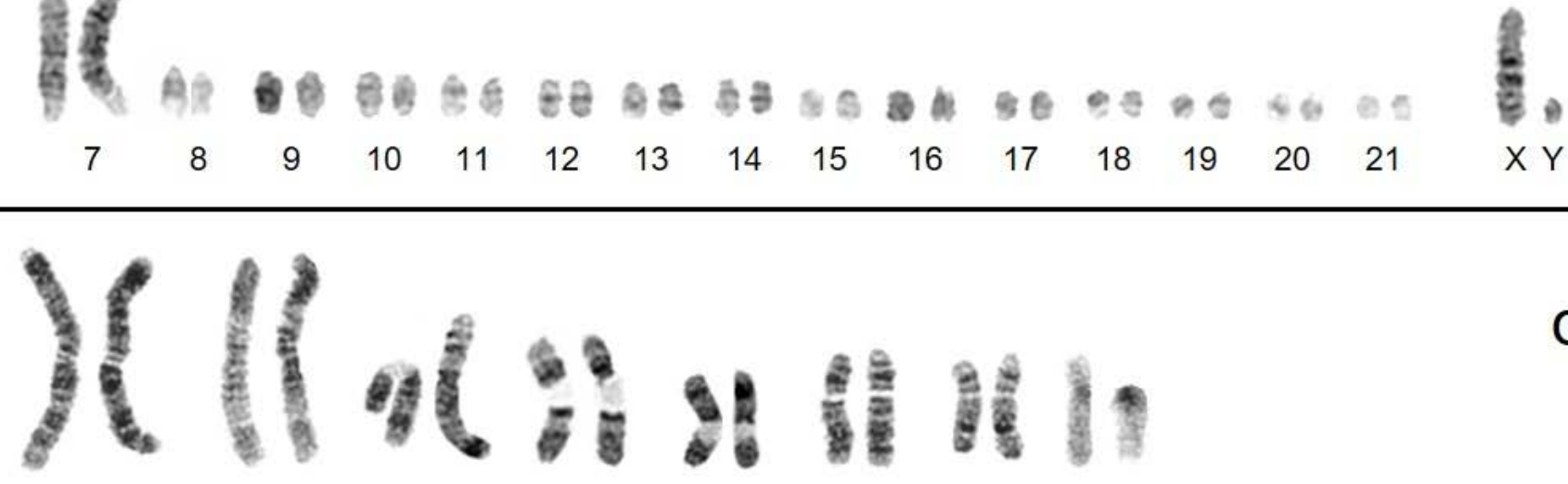

d

1
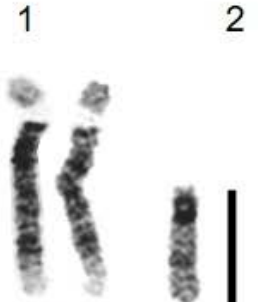

9

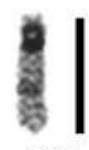

10

3

4

5

6

7

8

Figure 3. Representative DAPI karyotypes of the extant native Galápagos rodents. a) Aegialaomys galapagoensis, male. b) Nesoryzomys swarthi, female. c) Nesoryzon male. d) Nesoryzomys narboroughi, female. Chromosomes are numbered from longest to shortest, beginning with metacentrics and submetacentrics where present. 
dem fusions/fissions, inversions, translocations, or wholearm heterochromatin additions or deletions. Homologous chromosomes and portions of chromosomes are evident and a composite karyotype of the G-banded chromosomes for the four species was constructed using some of the larger chromosomes (Figure 4).

Robertsonian translocations are evident in some cases across all four extant species of Galápagos rodents. Chromosome 9 in N. narboroughi (Figure 3d) is a large, subtelocentric chromosome explained by the fusion of a small acrocentric chromosome to the largest acrocentric chromosome that is found to be homologous in all other species (Figure 4g). Chromosome 7 in N. narboroughi (Figure $3 \mathrm{~d}$ ) is a medium-sized metacentric chromosome that corresponds to smaller, acrocentric chromosomes in A. galapagoensis, N. swarthi, and N. fernandinae (Figure 4f). Homologous metacentric chromosomes were identified between $N$. fernandinae and N. narboroughi for Chromosomes 6 and 8 respectively, determined by the fusion of acrocentric chromosomes in A. galapagoensis and N. swarthi (Figure 4e). Chromosome 10 in N. narboroughi is a medium-sized subtelocentric chromosome (Figure $3 \mathrm{~d}$ ), its longer arm detected in both A. galapagoensis and N. swarthi but not $N$. fernandinae (Figure 4i). Chromosome 11 is the largest acrocentric chromosome in N. narboroughi (Figure $3 \mathrm{~d}$ ) and was identified in N. swarthi but could not be detected in other species (Figure 4j).

Chromosome 1 in both N. fernandinae and N. narboroughi is large and metacentric and nearly identical between the species, with the exception of a small addition on the end of $N$. narboroughi (Figure 4a), indicated by an asterisk $\left.{ }^{*}\right)$. Although some homologous portions of these chromosomes could be identified from both $N$. swarthi and $A$. galapagoensis, there are regions $\left(^{*}\right)$ that could not, either because of tandem fusions of smaller acrocentric chromosomes or insufficient staining quality. Similar observations can be made for Chromosome 3 in both N. fernandinae and N. narboroughi (Figure 4c).

Many of the chromosomes in N. narboroughi (Figure 3d) were found to be unique with variations that could not be found in the other species. It is possible that heterochromatic additions may play a role in these differences. Chromosome 4 in N. narboroughi is a metacentric chromosome with a homologous portion found in A. galapagoensis and $N$. swarthi but could not be identified in N. fernandinae. The lighter portion indicated by an asterisk (*) in Figure $4 \mathrm{~h}$ contains an area considered to be a heterochromatic addition. Chromosome 5 in $N$. narboroughi could not be resolved with other species, but likely contains a heterochromatic addition as seen in Chromosome 4, based on banding pattern. All species within Nesoryzomys possess an X chromosome that is mostly identical to each other when compared to Aegialomys, but with $N$. narboroughi differing slightly by a possible heterochromatic addition (Figure $2 \mathrm{~d}$ ).

\section{Discussion}

This is the first study to include karyotypes for all extant endemic rodent species of the Galápagos Islands. Our

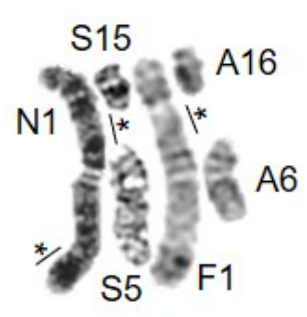

a

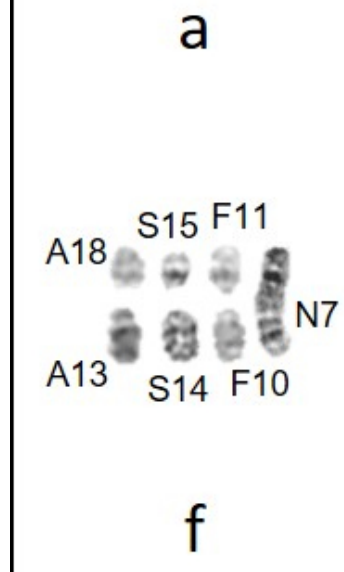

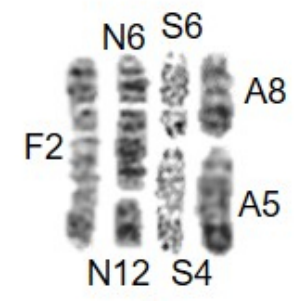

b

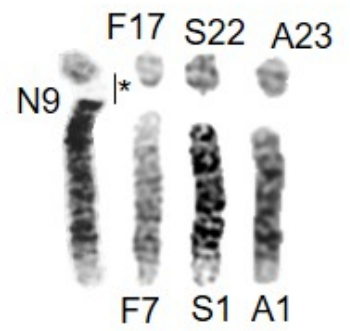

g

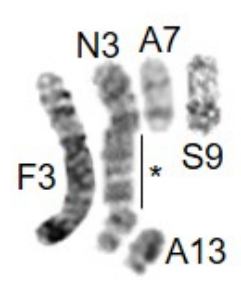

C

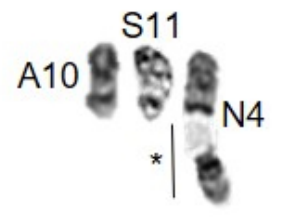

h
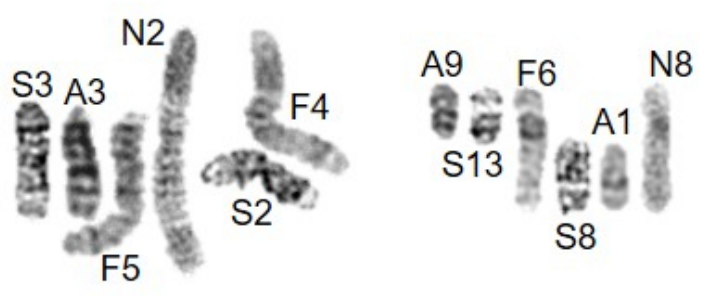

d

e
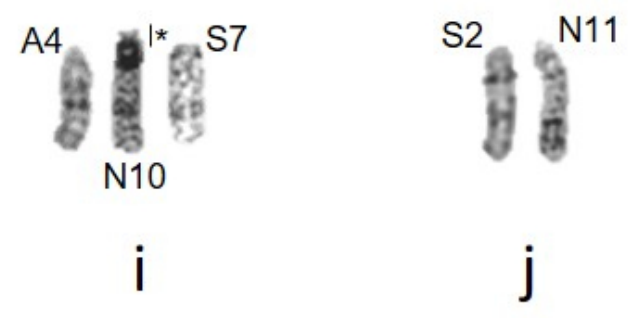

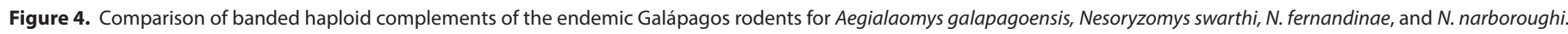

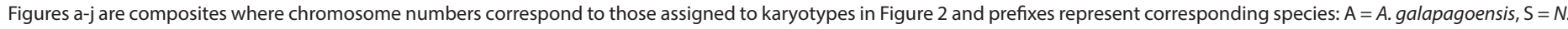
swarthi, $\mathrm{F}=\mathrm{N}$. fernandinae, $\mathrm{N}=\mathrm{N}$. narboroughi. Areas indicated by an asterisk $\left(^{*}\right)$ represent unique areas of chromosomes with unresolved homologies. 
karyotype for A. galapagoensis agrees with those reported by Gardner and Patton (1976) where they suggested that A. galapagoensis and A. xanthaeolus were identical in all aspects and perhaps were conspecific. Moreira et al. (2020), however, pointed out that Prado and Percequillo (2016) determined that the same specimens karyotyped as A. xanthaeolus by Gardner and Patton (1976) were from Peru and in fact belong to $A$. baroni and $A$. ica. Despite the fact that true $A$. xanthaeolus from Ecuador and northern Peru have yet to be karyotyped, the lack of apparent chromosomal variation among the three other species suggests that Aegialomys may be karyotypically monomorphic. Prado and Percequillo (2018) found that $A$. galapagoensis was sister to the two southern mainland forms A. baroni and A. ica, concluding that it is a unique species and lineage.

With respect to Nesoryzomys, surveys by our field teams and others over the last several decades suggest the two species from the island of Santa Cruz, N. darwini and N. indefessus (also from Baltra) likely have been extinct since the 1930s (Patton and Hafner 1983; Clark 1984; Dowler et al. 2000). In addition, three undescribed species occurred on the island of Rábida and Isabela but are extinct (Steadman et al. 1991). Thus, our karyotypic knowledge of the known Nesoryzomys fauna of eight species is restricted to those reported here. In contrast to the chromosomes of Aegialomys, our study reveals striking intrageneric variation in the karyotype of Nesoryzomys. Previously known only from $\mathrm{N}$. narboroughi, its aberrant arrangement of mostly biarmed chromosomes was used to establish generic status (Gardner and Patton 1976; Patton and Hafner 1983; Suárez-Villota et al. 2013; Moreira et al. 2020). We report two new additional, distinct karyotypes of the other Nesoryzomys that provide insight into the origin of such a unique arrangement and demonstrate a closer relationship with other oryzomyine sister taxa.

Of the four major clades (Clades A-D) described in the monophyletic lineage of oryzomyines (Weksler 2006), Nesoryzomys falls within Clade D. Within that group, Nesoryzomys is placed in the Aegialomys-Megalomys-MelanomysNesoryzomys-Oryzomys-Sigmodontomys-Tanyuromys clade (Pine et al. 2012; Salazar-Bravo et al. 2016; Timm et al. 2018) and most phylogenies agree that Nesoryzomys is sister to Aegialomys (Weksler 2003; Hanson and Bradley 2008; Pine et al. 2012; Machado et al. 2014; Parada et al. 2015; Steppan and Schenk 2017; Timm et al. 2018; Castañeda-Rico et al. 2019; Brito et al. 2020). Aegialomys galapagoensis shares the same $2 n=56$ karyotype as the mainland forms $A$. ica and A. baroni (Gardner and Patton 1976; Prado and Persequillo 2018), and N. swarthi but differs in fundamental numbers, $\mathrm{FN}=58$ in Aegialomys and $\mathrm{FN}=54$ in N. swarthi. The karyotype of $A$. galapagoensis comprises mostly acrocentric autosomes but has two small metacentric chromosomes that are absent in the entirely acrocentric karyotype of $N$. swarthi. No small metacentric chromosomes were found in any of the three species of Nesoryzomys that we examined, suggesting that these form a chromosomal group dis- tinct from that of Aegialomys. Homologies in N. swarthi are not apparent for the two small metacentric chromosomes in Aegialomys. Some molecular phylogenies have found Nesoryzomys to be sister with Sigmodontomys and Melanomys and these sister to A. xanthaeolus (Weksler 2003; Machado et al. 2014; Salazar-Bravo et al. 2016). Based on chromosomal morphology, Melanomys $(2 n=56, F N=58)$ differs from $N$. swarthi by its two small metacentric autosomes and subtelocentric sex chromosomes (Gardner and Patton 1976). All sex chromosomes found within Nesoryzomys are acrocentric. The karyotype of $N$. swarthi is identical with Sigmodontomys alfari $(2 \mathrm{n}=56, \mathrm{FN}=54)$ as described by Gardner and Patton (1976). Sigmodontomys aphrastus was elevated to generic status as Tanyuromys aphrastus by Pine et al. (2012), and S. alfari remained sister to Melanomys. No known karyotype for Tanyuromys is available for comparison. The relationship between Melanomys and Sigmodontomys has been found to be paraphyletic and new species have been described (Timm et al. 2018; Pine et al. 2012). The identical karyotype shared between S. alfari and $N$. swarthi could be convergent; however, future comparison of chromosomal rearrangements between these two could provide valuable insight on the chromosomal evolution of Nesoryzomys.

In considering Aegialomys as sister to Nesoryzomys, small metacentric chromosomes are absent in all karyotypes of Nesoryzomys and some small acrocentric chromosomes would likely be the result of a fission event that occurred sometime in the past. Given that up to five other endemic species are now extinct, it is probable that one of these may have retained a chromosomal arrangement identical to Aegialomys. These gaps will remain problematic in completely understanding the chromosomal evolution of the Galápagos endemic rodent fauna. With the available evidence, we propose that the $2 n=56$ karyotype is basal for the Nesoryzomys-Aegialomys clade (Figure 5).

Patton and Hafner (1983) concluded that the three large forms of Nesoryzomys (N. indefessus, N. narboroughi, and N. swarthi) all allopatrically distributed on different islands were conspecific based on similarity of specimen morphology. Diploid and fundamental numbers for both N. swarthi and $N$. narboroughi differ significantly, leaving no question that they are distinct species, and this also has been supported in all molecular studies that included both of these species (Weksler 2003; Pine et al. 2012; Leite et al. 2014; Parada et al. 2015; Steppan and Schenk 2017; CastañedaRico et al. 2019; Brito et al. 2020). The question of whether $N$. indefessus is conspecific with N. narboroughi as proposed by Patton and Hafner (1983) and adopted by Musser and Carleton (2005) is yet to be answered. Given that each species in the genus thus far has had such uniquely distinct karyotypes, we believe that there is a strong likelihood that $N$. indefessus, endemic to Santa Cruz and Baltra, would differ from the other large Nesoryzomys and should be recognized as such (Dowler 2015). Future molecular analysis that includes $N$. indefessus may be able to settle this issue. 
Both N. fernandinae and N. narboroughi on Isla Fernandina also differ markedly in diploid and fundamental number. The karyotype for $N$. fernandinae represents the only chromosomal data for the small body-size form in Nesoryzomys, the other being the presumed extinct $N$. darwini. This is the only case of sympatry among extant forms and both the karyotypic and morphological differences rule out any likelihood of hybridization between the two.

In addition to the obvious geographic barriers between island populations of organisms, chromosomal rearrangements are known to serve as reproductive barriers and can become established over short periods of time (Searle 1993; Moreira et al. 2020). Gardner and Patton (1976) established the foundation for understanding chromosomal evolution among the Sigmodontinae and suggested that the general trend for chromosomal evolution was one of decrease in both diploid and fundamental numbers. Moreira et al. (2020) concluded that chromosomal evolution of oryzomyines differ by a large variety of rearrangements and that diploid numbers both decrease and increase without any distinguishable pattern. In the case of the Galápagos endemic rodent fauna, we propose that speciation on the archipelago has resulted in a decrease in both diploid and fundamental numbers resulting from potentially rapid divergence as colonists arrived on unoccupied islands. Some of these speciation events may have been facilitated by chromosomal rearrangements (King 1993; BrittonDavidian et al. 2000; Wang and Lan 2000).

Of the 141 oryzomyine species for which karyotypic data exist, Moreira et al. (2020) reported that 55 included some chromosomal banding, but banded karyotypes only exist for members of Oryzomys outside the Galápagos rodent fauna (Haiduk et al. 1979) in the Aegialomys-Megalomys-Melanomys-Nesoryzomys-Oryzomys-SigmodontomysTanyuromys clade (Pine et al. 2012; Salazar-Bravo et al. 2016; Timm et al. 2018). This is the first study to include banded karyotypes for all extant endemic rodent species of the Galápagos Islands. Banding revealed extensive chromosomal rearrangements in the Galápagos rodents, a pattern that is clear in many other oryzomyines (Suárez-Villota et al. 2013; Suárez et al. 2015; Pereira et al. 2016). Despite the utility of chromosome banding as a tool in identifying and examining interspecies homologies (Damas et al. 2021), lack of banding data from those considered close relatives to the Galápagos rodents makes comparisons impossible at this time.

We identified numbers and types of chromosomal rearrangements using the largest chromosomes found in $N$. fernandinae and N. narboroughi (Figure 4) and demonstrate Robertsonian fusions, tandem fusions, other translocations, and some that could not be identified from banding sequences. The banding patterns between $N$. fernandinae and $N$. narboroughi revealed at least three whole chromosome homologies, at least one whole arm translocation, and evidence of tandem fusions when compared to $N$. swarthi and A. galapagoensis (Figure 4). Banding found in $N$. narboroughi revealed unique regions not found in any of the other Galápagos rodents with large heterochromatic additions. The difference in $2 \mathrm{n}$ but not $\mathrm{FN}$ between $\mathrm{N}$. swarthi and $N$. fernandinae also suggests Robertsonian fusions have occurred. These rearrangements could be supported further with C-banding, but we were unable to obtain

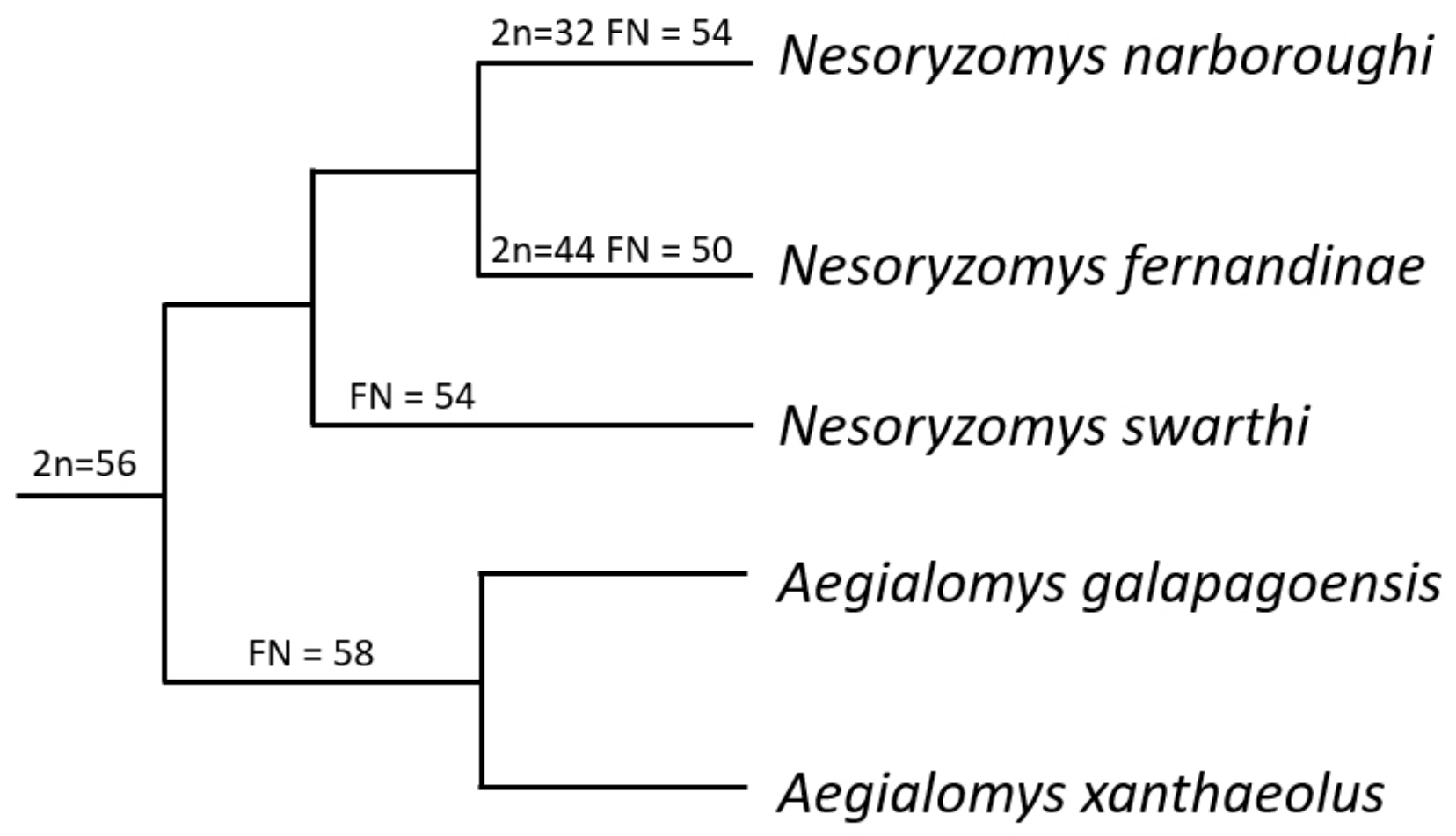

Figure 5. Cladogram depicting phylogeny of the native Galápagos rodents and Aegialomys xanthaeolus with chromosomal diploid (2n) and fundamental numbers (FN) included. 
these data. Castañeda-Rico et al. (2019) determined these two species to be sister to $N$. narboroughi based on mtDNA D-loop sequence data, as did Steppan and Schenk (2017) based on concatenated sequences of multiple genes. In contrast, N. narboroughi has been placed with N. swarthi in other molecular phylogenies (Parada et al. 2015; Brito et al. 2020), but with lower statistical support. Other molecular studies only have included two of the three species in their molecular analyses.

Moreira et al. (2020) examined the karyotypic variation among all Oryzomyini rodents and found the majority of species are composed of acrocentric chromosomes with a diploid number between 48 and 64 with fundamental numbers ranging from 56 to 74 . We use this generality to examine the evolutionary history of the native rodent fauna of the Galápagos Islands. Given that the chromosomal arrangements among the four extant species suggest a progressive reduction in the diploid number, the completely acrocentric karyotype of $\mathrm{N}$. swarthi $(2 \mathrm{~N}=56, \mathrm{FN}=54)$ should be regarded as the most representative of the ancestral form of the genus (Figure 5). The karyotypes of N. fernandinae $(2 \mathrm{n}=44, \mathrm{FN}=54)$ and $N$. narboroughi $(2 \mathrm{n}=32, \mathrm{FN}=$ 50) represent derived species with different chromosomal rearrangements resulting in both metacentric and subtelocentric chromosomes. Based on banding patterns, it is plausible to infer that $N$. fernandinae represents an intermediate stage of the genus, with rearrangements that carried into N. narboroughi. Garagna et al. (2014), when examining the Robertsonian phenomenon in the house mouse (Mus), stated that a high occurrence rate of Robertsonian fusions and whole arm translocations suggest that there are inherent genomic traits in the centromeric region that promote these rearrangements. The differences in sex chromosomes between Nesoryzomys and Aegialomys further support that the ancestral form for Nesoryzomys is unique relative to present day Aegialomys occurring on the islands. Searle (1993) suggested that mutations in chromosomal races that lead to metacentric chromosomes contribute to increasing reproductive isolation and, in time, to speciation.

Colonization of oryzomyine rodents in the Galápagos Islands represents the greatest overwater dispersal distance for terrestrial mammals (Pine et al. 2012) and these rodents are the only terrestrial mammals that have naturally colonized and diversified within the archipelago. Nesoryzomys is known to occur on at least 6 of the 13 major islands (Harris and Macdonald 2007), which date from up to 3.5 to 4 mya to 60,000 ya (Geist et al. 2014). Garagna et al. (2014) stated that the best place to search for extremes in chromosomal variation is in geographically isolated populations. Piálek et al. (2005), in examining chromosomal variation in European Mus, identified 'islands' of Mus occurring in the Swiss Alps. The standard karyotype of Mus is an all telocentric karyotype $(2 n=40)$, but metacentric rearrangements occurred in these 'island' populations and these polymorphisms have the potential to become fixed. In laboratory stocks of Mus domesticus, it was observed that once a Rob- ertsonian fusion occurred, it acted as an 'infectious agent' and other fusions quickly followed, something that could occur in wild populations (Nachman and Searle 1995). King (1993), in discussing the role of chromosome change and species evolution, stated that it is evident that the formation of Robertsonian fusion events leading to metacentric chromosomes arise and spread in populations, constituting one of the main sources for karyotype evolution in mammals. Centromeres and telomeres play a role in maintaining genome stability and changes in chromosome number can result in centromere repositioning over time (Damas et al. 2021). These can become fixed by selection when fusion events are associated with changes in gene expression or meiotic drive and act as a reproductive barrier and promote speciation. A Robertsonian event may lead to a significant reduction in the DNA sequence that organizes the centromere making it difficult to regenerate functional telocentric chromosomes (Garagna et al. 1995). This suggests a tendency of ancestral all-telocentric karyotypes moving toward accumulation of metacentric chromosomes but without reverse tendencies towards fission events that result in telocentric chromosomes, once a largely metacentric karyotype has been established (Garagna et al. 2014). The chromosomes of the endemic Galápagos rodent fauna appear to follow these patterns.

The colonization history of native rodents in the Galápagos Islands and its timing continue to be uncertain. Most have supported the idea of three separate colonization events from mainland South America or Central America for each of the rodent genera, with Megaoryzomys the oldest, Nesoryzomys next and more recently, Aegialomys (Patton and Hafner 1983; Parent et al. 2008; Pine et al. 2012). For the extant genera, Aegialomys and Nesoryzomys, molecular phylogenies suggest they diverged in the Pliocene about 3.84 mya based on mtDNA D-loop sequences (CastañedaRico et al. 2019), although others have estimated their divergence at about 2.8 mya (Parada et al. 2015) and in the Pleistocene from 1.49 mya (Machado et al. 2014) and 2.4 mya (Parada et al. 2013). Some of this discrepancy is a result of Castañeda-Rico et al. (2019) using an origin of the Galápagos in their calculations of 5 mya based on Geist et al. (2014) whereas Machado et al. (2014) used 4 mya based on Geist (1984). Species divergences within Nesoryzomys occurred in the early Pleistocene about 2.23 mya between the clade represented by $N$. swarthi/N. fernandinae and $N$. narboroughi. This was followed by the divergence of $N$. swarthi and $N$. fernandinae at 1.58 mya (Castañeda-Rico et al. 2019). Most other studies that have attempted to date the divergence of oryzomyines also have placed the divergence of Nesoryzomys species in the Pleistocene (Parada et al. 2013; Leite et al. 2014; Parada et al. 2015).

An explanation of the sequence of colonization events that resulted in the seven known taxa of Nesoryzomys is likely impossible based on the geologic history of the Galápagos Islands. Recent studies by Ali and Aitchison (2014) and Geist et al. (2014) proposed that this archipelago's pat- 
tern of subsidence and sea level changes have resulted in multiple small and large previous islands that were available for further isolation of evolving taxa. This phenomenon has alternated with sea level declines that allowed movement of populations across previous oceanic barriers between currently recognized islands. Geist et al. (2014) proposed that for lava lizards (Microlophus), both dispersal and vicariant allopatric speciation occurred based on the subsidence and sea level changes that shifted the amount of land area in the Galápagos Islands. For Nesoryzomys, a similar phenomenon may well have occurred. Dispersal and allopatric speciation allowed the oryzomyines that first colonized the islands, potentially Sigmodontomys or related forms, to diverge from these previous mainland ancestors. Following that event, a series of speciation events occurred, some by further dispersal to newly arising islands and others by vicariance. As sea level first declined during glacial events to unite land masses, such as the uniting of the central 'core' islands that included Santa Fé, Santiago, Isabela, and Fernandina, overland dispersal could occur for once isolated forms. As sea level then rose during interglacial periods, these larger islands were once again divided, isolating their flora and fauna. Ali and Aitchison (2014) compare patterns of distribution for most of the nonmammalian vertebrates (reptiles and Darwin's finches) and Scalasia land plants of the Galápagos. The known endemic rodents in the genus Nesoryzomys all follow a distribution in the 'core' area of the archipelago. These patterns of recurring isolation followed by widespread dispersal could well have provided a sufficient mechanism for the origin of the extensive chromosomal shuffling that is apparent in the three extant Nesoryzomys species and that likely occurred among all the existing forms of the genus.

Many oryzomyine rodents possess species-specific karyotypes (Gardner and Patton 1976; Suárez-Villota et al. 2013; Di-Nizo et al. 2017; Moreira et al. 2020) and provide ample evidence that chromosomal rearrangements contribute to the process of speciation (Damas et al. 2021). Thus, identification of chromosomal rearrangements contributes to our understanding of chromosomal evolution within Nesoryzomys. The role of chromosomal rearrangements has been a point of discussion for over half a century and chromosomes remain a valuable tool in systematics as they combine both morphological and genetic character traits, and represent the elements of variation and heredity (Bakloushinskaya 2016). Damas et al. (2021) suggested that chromosomal rearrangements are both a critical mechanism of reproductive isolation and a source of genetic variation that contributes to novel and adaptive traits during and after speciation has occurred. Adaptability applies not only to the organism as a whole but also to the genome, the structure of which changes under selection (Bakloushinskaya 2016). Charles Darwin, in formulating his concept of natural selection that originated from observations made on the Galápagos Islands, knew that natural selection occurs because of variation in a population (Darwin 1859).
Yet, the mechanisms for which chromosomal variation give way to speciation is still not clearly understood. With few exceptions, both the $2 \mathrm{n}$ and $\mathrm{FN}$ are relatively constant in the known karyotypes found within the Aegialomys-Megalomys-Melanomys-Nesoryzomys-Oryzomys-SigmodontomysTanyuromys clade, suggesting a stable karyotype that is not drastically changed by speciation events. The lone exception from those taxa that have karyotypic data is the genus Nesoryzomys. Based on what we understand of the chromosomal variation in these endemic rodents of the Galápagos Islands, chromosomal rearrangements either result from or play a key role in island speciation and adaptability of a population over time.

\section{Acknowledgments}

We dedicate this paper to David J. Schmidly, the Ph.D. advisor of one of us (RCD), our respected colleague for many decades, and a friend. Dr. Schmidly made many contributions to a better understanding of mammals, the history of North American mammalogy, and the conservation of biodiversity, as well as his inspiring (MAR) and training of another generation of mammalogists. These are a fitting legacy capping off a remarkable career.

Our thanks to the staff of the Estación Cientifica Charles Darwin and the Charles Darwin Foundation. Permits were provided by the Parque Nacional Galápagos. TAME Airlines gave discounts for researchers. Funding was provided by the National Geographic Society (\#6517-99) and the Angelo State University Research Enhancement Grant Program. Many thanks go to the field team who helped collect specimens including J. Flanagan, N. Dexter, and S. Hart. Special thanks to the Department of Biology at Texas Tech University for allowing use of equipment and laboratory space, particularly B. E. Rodgers and D. Parish for assistance in preparing karyotypes. We also are thankful to the Angelo State Natural History Collections for use of the specimens. We appreciate the assistance of B. R. Skipper and G. R. Xiang in preparation of figures, and S. B. González-Pérez for translating our abstract.

\section{Literature Cited}

Alı, J. R., ANd J. C. Aitchison. 2014. Exploring the combined role of eustasy and oceanic island thermal subsidence in shaping biodiversity on the Galápagos. Journal of Biogeography 41:1227-1241.

Allen, J. A. 1892. On a small collection of mammals from the Galápagos Islands, collected by G. Baur. Bulletin of the American Museum of Natural History 4:47-50.

Bakloushinskaya, I. Y. 2016. Chromosomal rearrangements, genome reorganization, and speciation. Biology Bulletin 43:1-17. Brito J., C. Koch, A. R. Percequillo, N. Tinoco, M. Weksler, C. M. Pinto, and U. F. J. Pardiñas. 2020. A new genus of oryzomyine rodents (Cricetidae, Sigmodontinae) with three new species from montane cloud forests, western Andean cordillera of Colombia and Ecuador. PeerJ 8:e10247 DOI 10.7717/ peerj.10247. 
Britton-Davidian, J., J. Catalan, M. G. Ramalhinho, G. Ganem, J. C. Auffray, R. Capela, M. Biscoito, J. B. Searle, and M. L. MathIAS. 2000. Rapid chromosomal evolution in island mice. Nature 403:158. https://doi.org/10.1038/35003116.

Brosset, A. 1963. Statut actuel des mammifères des îles Galapagos. Mammalia 27:323- 338.

Castañeda-Rico, S. A. Johnson, S. A. Clement, R. C. Dowler, J. E. Maldonado, and C. W. Edwards. 2019. Insights into the evolutionary and demographic history of the extant endemic rodents of the Galapágos Islands. Therya 10:213-228.

Clark, D. A. 1984. Native land mammals. Pp. 225-231, in Key environments: Galápagos (Perry, R., ed.). Pergamon. Oxford, UK.

Damas, J., M. Corbo, and H. A. Lewin. 2021. Vertebrate chromosome evolution. Annual Review of Animal Biosciences 9:9.1-27.

DARwin, C. 1859. On the origin of species by means of natural selection, or, the preservation of favoured races in the struggle for life. J. Murray. London, England.

Di-Nizo, C. B., K. Rodrigues de Silva Banci, Y. Sato-Kuwabara, M. José DE J. Silva. 2017. Advances in cytogenetics of Brazilian rodents: cytotaxonomy, chromosome evolution and new karyotypic data. Comparative Cytogenetics 11:833-392.

Dowler, R. C. 2015. Genus Nesoryzomys. Pp. 390-393, in Mammals of South America. Volume 2, Rodents, (Patton, J. L., U. F. J. Pardiñas, and G. D'Elía, eds.). The University of Chicago Press. Chicago, U.S.A.

Dowler, R. C., and D. S. Carroll. 1996. The endemic rodents of Isla Fernandina: Population status and conservation issues. Noticias de Galápagos 57:8-13.

Dowler, R. C., D. S. Carroll, and C. W. Edwards. 2000. Rediscovery of rodents (Genus Nesoryzomys) considered extinct in the Galápagos Islands. Oryx 34:109-117.

Ellerman, J. R. 1941. The families and genera of living rodents. Vol. II. Family Muridae. British Museum (Natural History). London, England.

Garagna S, D. Broccoli, C. A. Redi, J. B. Searle, H. J. Cook, and E. Capanna. 1995. Robertsonian metacentrics of the house mouse lose telomeric sequences but retain some minor satellite DNA in the pericentromeric area. Chromosoma 103:685-692.

Garagna, S. J. Page, R. Fernandez-Donoso, M. Zuccotti, and J. B. SEARLE. 2014. The Robertsonian phenomenon in the house mouse: mutation, meiosis and speciation. Chromosoma 123. DOI 10.1007/s00412-014-0477-6.

Gardner, A. L., AND J. L. Patton. 1976. Karyotypic variation in oryzomyine rodents (Cricetinae) with comments on chromosomal evolution in the Neotropical cricetine complex. Occasional Papers of the Museum of Zoology, Louisiana State University 49:1-48.

GeIST, D. 1984. On the emergence and submergence of the Galápagos Islands. Noticias de Galápagos 56:5-9.

Geist, D. J., H. Snell, H. Snell, C. Goddard, and M. D. Kurz. 2014. A paleogeographic model of the Galápagos Islands and biogeographical and evolutionary implications. Pp. 143-164, in The Galápagos: a natural laboratory for earth sciences (Harpp, K. S., E. Mittelstaedt, N. d'Ozouville, and D. W. Graham eds.). https://doi.org/10.1002/9781118852538.ch8.

Haiduk, M. W., J. W. Bickham, And D. J. Schmidly. 1979. Karyotypes of six species of Oryzomys from Mexico and Central America. Journal of Mammalogy 60:610-615.
Hanson J. D., and R. D. Bradley. 2008. Molecular diversity within Melanomys caliginosus (Rodentia: Oryzomyini): evidence for multiple species. Occasional Papers, Museum of Texas Tech University 275:1-11.

HarRis, D. B., ANd D. W. Macdonald. 2007. Population ecology of the endemic rodent Nesoryzomys swarthi in the tropical desert of the Galápagos Islands. Journal of Mammalogy 88:208-219.

Heller, E. 1904. Mammals of the Galapágos Archipelago, exclusive of the Cetacea. Proceedings of the California Academy of Sciences 3:233-251.

Heng, H. Q. G., AND L. C. Tsul. 1993. Modes of DAPI banding and simultaneous in situ hybridization. Chromosoma 102:325-332.

Hutterer, R., ANd U. HiRsch. 1979. Ein neuer Nesoryzomys von der Insel Fernandina, Galápagos. Bonner Zoologische Beitrage 30:276-283

Key, G., ANd E. Muñoz Heredia. 1994. Distribution and current status of rodents in the Galápagos. Noticias de Galápagos 53:21-25.

KING, M. 1993. Species evolution: the role of chromosome change. Cambridge University Press, Cambridge, England.

Lee, M. R., ANd F. F. B. Elder. 1980. Yeast stimulation of bone marrow mitosis for cytogenetic investigations. Cytogenetics and Cell Genetics 26:36-40.

Leite, R. N., S. O. Kolokotronis, F. C. Almeida, F. P. Werneck, D. S. Rogers, AND M. WeKsLer. 2014. In the wake of invasion: tracing the historical biogeography of the South American Cricetid radiation (Rodentia, Sigmodontinae). PLOS ONE 9:1-12.

Machado, L. F., Y. L. R. Leite, A. U. Christoff, and L. G. Giugliano. 2014. Phylogeny and biogeography of tetralophodont rodents of the tribe Oryzomyini (Cricetidae: Sigmodontinae). Zoologica Scripta 43:119-130.

Moreira, C. N., K. Ventura, A. R. Percequillo, and Y. YonenagaYASSUDA. 2020. A review on the cytogenetics of the tribe Oryzomyini (Rodentia: Cricetidae: Sigmodontinae), with the description of new karyotypes. Zootaxa 4876:1-111.

Musser, G. G., ANd M. D. Carleton. 2005. Superfamily Muroidea. Pp. 894-1531, in Mammal species of the world: a taxonomic and geographic reference, 3rd ed. (Wilson, D. L., and D. M. Reeder, eds.). The Johns Hopkins University Press. Baltimore, U.S.A.

Nachman, M. W., and J. B. Searle. 1995. Why is the house mouse karyotype so variable? Trends in Ecology and Evolution 10:397-402.

ORR, R.T. 1938. A new rodent of the genus Nesoryzomys from the Galápagos Islands. Proceedings of the California Academy of Sciences, $4^{\text {th }}$ Series 23:303-306.

OsGood, W. H. 1929. A new rodent from the Galápagos Islands. Field Museum of Natural History, Zoological Series 17:21-24.

Parada, A., G D'Elia, and R. E. Palma. 2015. The influence of ecological and geographical context in the radiation of Neotropical sigmodontine rodents. BMC Evolutionary Biology 15:17.2

Parada, A., U. F. J. Pardiñas, J. Salazar-Bravo, G. D'Elía, and R. E. Palma. 2013. Dating an impressive Neotropical radiation: Molecular time estimates for the Sigmodontinae (Rodentia) provide insights into its historical biogeography. Molecular Phylogenetics and Evolution 66:960-968. 
Parent, C. E., A. Caccone, And K. Petren. 2008. Colonization and diversification of Galápagos terrestrial fauna: a phylogenetic and biogeographical synthesis. Philosophical Transactions of the Royal Society B 363:3347-3361.

Patton, J. L., and M. S. Hafner. 1983. Biosystematics of the native rodents of the Galápagos Archipelago, Ecuador. Pp. 539568 , in Patterns of evolution in Galápagos organisms (Bowman, R. I., M. Berson, and A. E. Leviton, eds.). AAAS Pacific Division. San Francisco, U.S.A.

Pereira, A. L., S. M. Malcher, C. Y. Nagamachi, P. C. M. O'Brien, M. A. Ferguson-Smith, A. C. Mendes-Oliveira, and J. C. PiecZARKA. 2016. Extensive chromosomal reorganization in the evolution of new world muroid rodents (Cricetidae, Sigmodontinae): searching for ancestral phylogenetic traits. Plos One 11: e0146179. doi:10.1371/journal.pone.0146179.

Peterson, R. L. 1966. Recent mammal records from the Galápagos Islands. Mammalia 30:441-445.

Piálek, J., H. C. Hauffe, J. And B. Searle. 2005. Chromosomal variation in the house mouse. Biological Journal of the Linnean Society 84:535-563.

Pine, R. H., R. M. Timm, And M. Weksler. 2012. A new recognized clade of trans-Andean Oryzomyini (Rodentia: Cricetidae), with description of a new genus. Journal of Mammalogy 93:851-870.

Prado, J. R., And A. R. Percequillo. 2016. Systematic studies of the genus Aegialomys Weksler, Percequillo and Voss, 2006 (Rodentia: Cricetidae: Sigmodontinae): Annotated catalogue of the types of the species-group taxa. Zootaxa 4144:477498. https://doi.org/10.11646/zootaxa.4144.4.2.

Prado, J. R., And A. R. Percequillo. 2018. Systematic studies of the genus Aegialomys Weksler et al., 2006 (Rodentia: Cricetidae: Sigmodontinae): geographic variation, species delimitation, and biogeography. Journal of Mammalian Evolution 25:71-118. DOI 10.1007/s10914-016-9360-y.

Salazar-Bravo, J., U. F. J. Pardinas, H. Zeballos, and P. Teta. 2016. Description of a new tribe of sigmodontine rodents (Cricetidae: Sigmodontinae) with an updated summary of valid tribes and their generic contents. Occasional Papers, Museum of Texas Tech University 338:1-23.

Searle, J. B. 1993. Chromosomal hybrid zones in eutherian mammals. Pp. 309-353, in Hybrid zones and the evolutionary process (Harrison, R. G., ed.). Oxford University Press. New York, U.S.A.

Snell, H. M., H. L. Snell, G. Davis-Merlen, T. Simkin, and R. E. SilBERGLIED. 1996. Bibliographía de Galápagos 1535-1995 Galápagos Bibliography. Fundación Charles Darwin para las Islas Galápagos, Quito, Ecuador.

Steadman, D. W., And C. E. Ray. 1982. The relationships of Megaoryzomys curioi, an extinct cricetine rodent (Muroidea: Muridae) from the Galapágos Islands, Ecuador. Smithsonian Contributions to Paleontology 51:1-23.

Steadman, D. W., T. W. Stafford, JR., D. J. Donahue, and A. J. T. JuLl. 1991. Chronology of Holocene vertebrate extinction in the Galápagos Islands. Quaternary Research 36:126-133.

Steppan, S. J., AND J. J. Schenk. 2017. Muroid rodent phylogenetics: 900-species tree reveals increasing diversification rates. Plos One 12:e0183070.

Suárez, P., C. Y. Nagamachi, C. Lanzone, M. M. Malleret, P. C. M. O’Brien, M. A. Ferguson-Smith, and J. C. Pieczarka. 2015. Clues on syntenic relationships among some species of Oryzomyini and Akodontini tribes (Rodentia: Sigmodontinae). Public Library of Science One, 10:1-12. e0143482.

Suárez-Villota, E. Y., C. B. Di-Nizo, C. L. Neves, and M. J. J. Silva. 2013. First cytogenetic information for Drymoreomys albimaculatus (Rodentia, Cricetidae), a recently described genus from Brazilian Atlantic Forest. ZooKeys 300:65-76.

Tномаs, O. 1899. Descriptions of new Neotropical mammals. Annals \& Magazine of Natural History, Series 7, 4:278-288.

Timm, R. M., R. H. Pine, ANd J. D. Hanson. 2018. A new species of Tanyuromys Pine, Timm, and Weksler, 2012 (Cricetidae: Oryzomyini), with comments on relationships within the Oryzomyini. Journal of Mammalogy 99:608-623.

WANG, W., AND H. LAN. 2000. Rapid and parallel chromosomal number reductions in muntjac deer inferred from mitochondrial DNA phylogeny. Molecular Biology and Evolution 17:1326-1333.

Waterhouse, G. R. 1839. The zoology of the voyage of H.M.S. Beagle, under the command of Captain Fitzroy, R. N., during the years 1832 to 1836 . Part 2. Mammalia. Smith, Elder and Co., London, England.

Weksler, M. 2003. Phylogeny of Neotropical oryzomyine rodents (Muridae: Sigmodontinae) based on the nuclear IRBP exon. Molecular Phylogenetics and Evolution 29:331-349.

Weksler, M. 2006. Phylogenetic relationships of oryzomyine rodents (Muridae: Sigmodontinae): separate and combined analyses of morphological and molecular data. Bulletin of the American Museum of Natural History 196:1-149.

Weksler, M., A. R. Percequillo, And R. S. Voss. 2006. Ten new genera of oryzomyine rodents (Muridae: Sigmodontinae). American Museum Novitates 3537:1-29.

Associated editor: Lisa and Robert Bradley

Submitted: January 29, 2021; Reviewed: March 8, 2021

Accepted: April 13, 2021; Published on line:May 28, 2021. 


\section{Appendix 1}

Specimens examined. Acronym for Angelo State Natural History Collections is ASNHC.

Aegialomys galapagoensis (3). ECUADOR: Galápagos Islands, Santa Fé, $-0^{\circ} 48.21^{\prime} \mathrm{S},-90^{\circ} 2.45^{\prime} \mathrm{W}$ (ASNHC 10613, ASNHC 10614, ASNHC 10615).

Nesoryzomys swarthi (4). ECUADOR: Galápagos Islands, Santiago, La Bomba, $-0^{\circ} 11.21^{\prime} \mathrm{S},-90^{\circ} 42.04^{\prime} \mathrm{W}$ (ASNHC 10597, ASNHC 10598, ASNHC 10599, ASNHC 10601).

Nesoryzomys fernandinae (4). ECUADOR: Galápagos Islands, Fernandina, Cabo Douglas, $-0^{\circ} 18.24^{\prime} \mathrm{S},-91^{\circ} 39.14^{\prime}$ W (ASNHC 10578, ASNHC 10579, ASNHC 10580, ASNHC 10581).

Nesoryzomys narboroughi (4). ECUADOR: Galápagos Islands, Fernandina, Punta Espinoza, $-0^{\circ} 15.96^{\prime} \mathrm{S}$, $-91^{\circ} 26.79^{\prime}$

W (ASNHC 10591, ASNHC 10594, ASNHC 10595); Galápagos Islands, Fernandina, Cabo Douglas, $-0^{\circ} 18.24^{\prime} \mathrm{S},-91^{\circ} 39.14^{\prime}$ W (ASNHC 10587). 
